\title{
Spontaneous perforation of gallbladder with intrahepatic biloma formation: sonographic signs and correlation with computed tomography*
}

\author{
Perfuração espontânea da vesícula biliar com formação de biloma intra-hepático: sinais ultrassonográficos \\ e correlação com tomografia computadorizada
Erick Sabbagh de Hollanda ${ }^{1}$, Ulysses dos Santos Torres $^{1}$, Fabiana Gual ${ }^{1}$, Eduardo Portela de Oliveira $^{1}$, Luciana Vargas Cardoso ${ }^{2}$, Divanei Aparecida Bottaro Criado ${ }^{3}$

\begin{abstract}
Spontaneous perforation of gallbladder is a severe and infrequent complication of acute cholecystitis that requires early and accurate diagnosis. Concomitant development of intrahepatic collections is rarely observed in such cases. The present report emphasizes the relevance of imaging studies in this setting, describing the typical sonographic and tomographic findings for the diagnosis of such condition.

Keywords: Gallbladder; Spontaneous rupture; Ultrasonography; Computed tomography.

Resumo A perfuração espontânea da vesícula biliar é uma complicação grave e pouco frequente da colecistite aguda, que exige diagnóstico rápido e preciso; a formação concomitante de coleções intra-hepáticas nesses casos é rara. 0 presente relato enfatiza a importância dos exames de imagem nesse contexto, demonstrando sinais ultrassonográficos e tomográficos típicos para o diagnóstico.

Unitermos: Vesícula biliar; Ruptura espontânea; Ultrassonografia; Tomografia computadorizada.

Hollanda ES, Torres US, Gual F, Oliveira EP, Cardoso LV, Criado DAB. Spontaneous perforation of gallbladder with intrahepatic biloma formation: sonographic signs and correlation with computed tomography. Radiol Bras. 2013 Set/Out;46(5):320-322.
\end{abstract}

\section{INTRODUCTION}

Spontaneous perforation of gallbladder (GB) is one of the most severe complications from acute cholecystitis. It is a rare condition, associated with high morbimortality, with reported mortality rates ranging between $12 \%$ and $42 \%{ }^{(\mathbf{1 , 2})}$. Although early diagnosis and management are fundamental, preoperative diagnosis is still considered difficult, and in most of cases the condition is diagnosed only during surgery ${ }^{(\mathbf{1})}$.

* Study developed in the Service of Radiology and Imaging Diagnosis at Hospital de Base -Faculdade de Medicina de São José do Rio Preto (Famerp), São José do Rio Preto, SP, Brazil.

1. MDs, Residents, Service of Radiology and Imaging Diagnosis of Hospital de Base - Faculdade de Medicina de São José do Rio Preto (Famerp), São José do Rio Preto, SP, Brazil.

2. MD, Radiologist, Head of the Unit of Computed Tomography, Service of Radiology and Imaging Diagnosis, Hospital de Base - Faculdade de Medicina de São José do Rio Preto (Famerp), São José do Rio Preto, SP, Brazil.

3. Fellow Master degree in Health Sciences, MD, Radiologist, Unit of Ultrasonography, Service of Radiology and Imaging Diagnosis, Hospital de Base - Faculdade de Medicina de São José do Rio Preto (Famerp), São José do Rio Preto, SP, Brazil.

Mailing Address: Dr. Ulysses dos Santos Torres. Hospital de Base da Faculdade de Medicina de São José do Rio Preto, Serviço de Radiologia e Diagnóstico por Imagem. Avenida Brigadeiro Faria Lima, 5544, Vila São Pedro. São José do Rio Preto, SP, Brazil, 15090-000. E-mail: usantor@yahoo.com.br.

Received January 5, 2013. Accepted after revision April 1st, 2013.
Cases of GB perforation concomitantly with development of bilomas or intrahepatic abscesses, like in the present report, are even rarer, with few cases described in the literature ${ }^{(3,4)}$.

The present report describes a preoperatively diagnosed case, with emphasis on typical sonographic signs in correlation with tomographic findings.

\section{CASE REPORT}

A 50-year-old, male patient was admitted to the emergency department with abdominal pain in the right upper quadrant for five days, non-measured fever, nausea, emesis and jaundice. At clinical examination, the patient was febrile, slightly icteric, with pain at palpation on his right upper quadrant, besides the presence of Murphy sign. Laboratory tests revealed the presence of leukocytosis, increased serum levels of glutamyl transferase and direct hyperbilirubinemia. Abdominal ultrasonography was performed, demonstrating signs of acute cholecystitis as well as an extensive defect in the anterior wall of the GB with development of a circumjacent anechoic collec- tion in close contact with the right liver lobe (Figure 1). Also, dilatation of intra- and extrahepatic biliary ducts was observed, without determining the site of obstruction. With the diagnostic hypothesis of GB perforation in association with biloma, the patient was submitted to abdominal computed tomography (CT), which confirmed the parietal perforation of the GB and allowed the characterization of the collection as an intrahepatic subcapsular biloma, as well as the visualization of an impacted calculus in the duodenal papilla (Figure 2). The patient underwent open cholecystectomy with biloma drainage, and later retrograde endoscopic cholangiopancreatography, with removal of an impacted calculus located in the major duodenal papilla. The patient progressed favorably and was asymptomatic at discharge one week after his admission.

\section{DISCUSSION}

Spontaneous (non-traumatic) GB perforation is not frequently found, occurring in $2 \%$ to $10 \%$ of cases of acute cholecystitis ${ }^{(\mathbf{4})}$. Because of the increase in cholecystecto- 


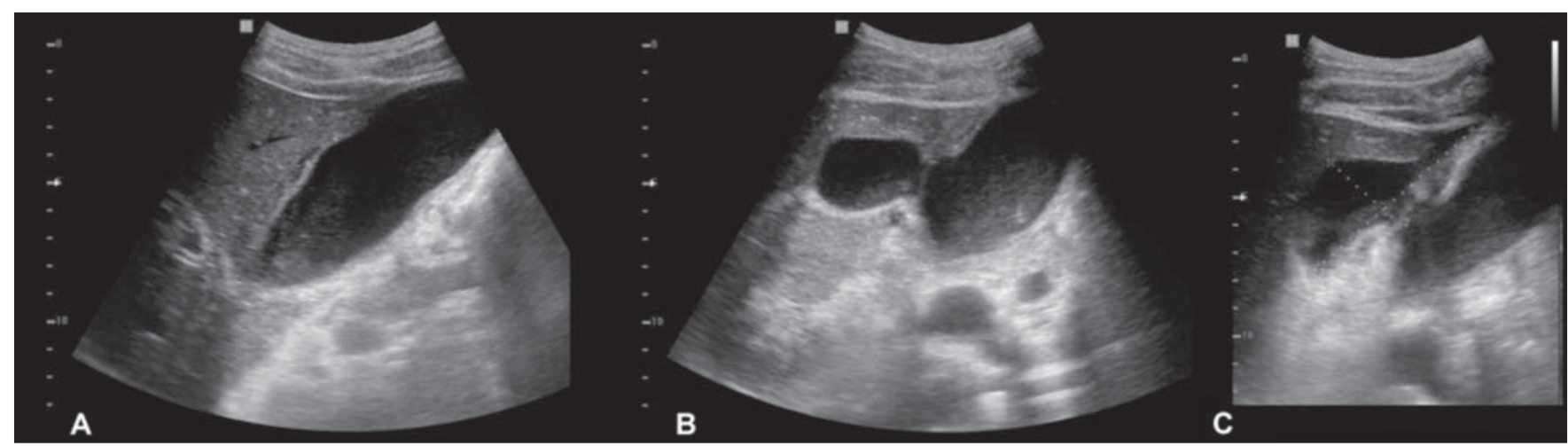

Figure 1. A: Sonographic findings demonstrating subtle GB wall thickening, pericholecystic fluid and presence of GB sludge. B,C: Also, an extensive defect (perforation) is observed in the anterior wall of the GB (hole sign), with development of a predominantly anechoic perihepatic collection suggestive of biloma.

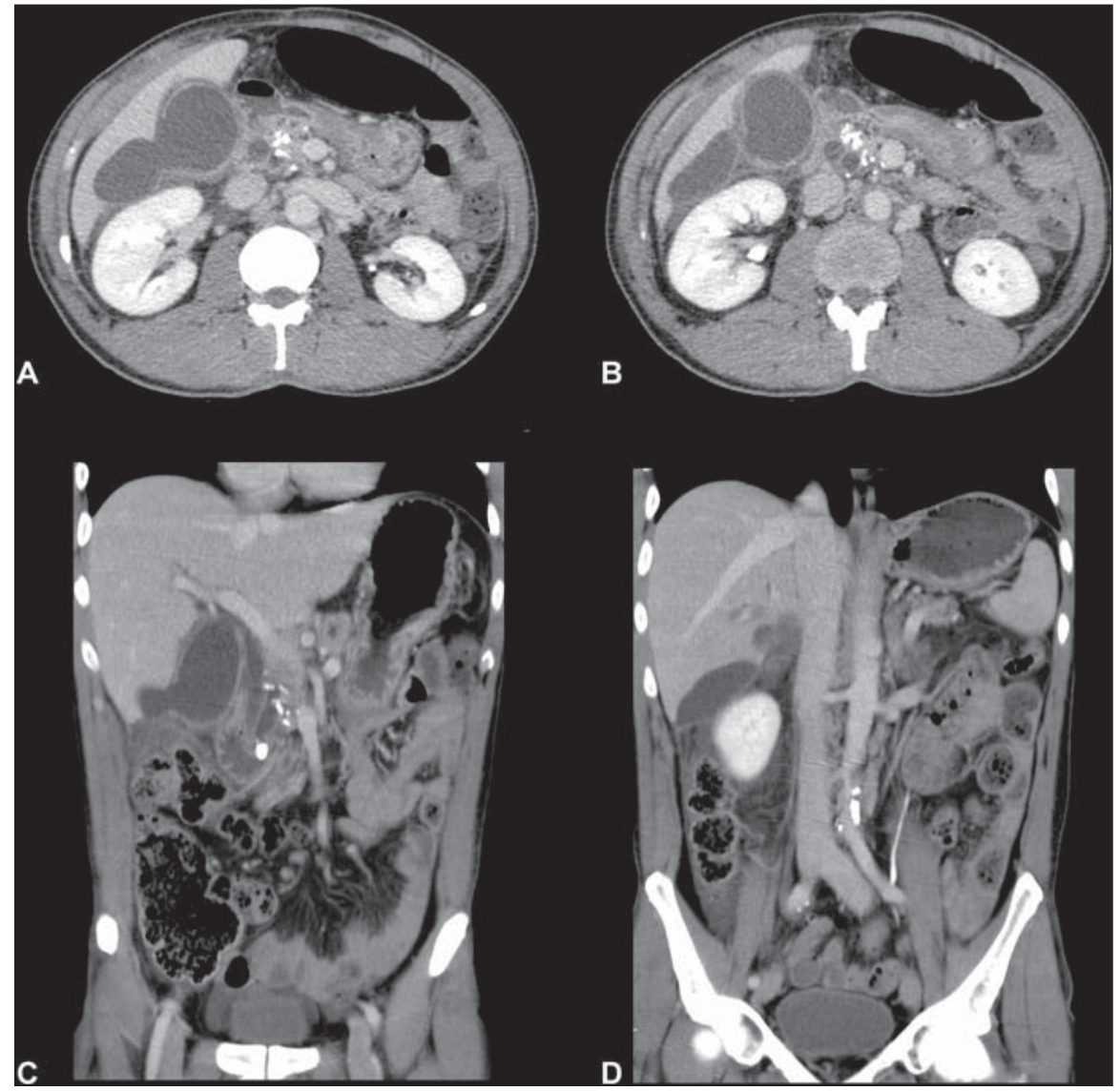

Figure 2. A,B: Axial sections, portal phase of abdominal computed tomography revealing the GB with a thickened and enhancing wall, pericholecystic fluid, an area of wall defect (perforation) (tomographic hole sign), besides the presence of a homogeneously hypodense, non-enhancing, subcapsular intrahepatic collection, suggestive of biloma. Observe the additional findings of foci of gross pancreatic calcifications and dilated Wirsung and choledocal ducts. C,D: Coronal reconstructions of portal phase confirm the previous findings, demonstrating the cause of the process (impacted calculus in the duodenal papilla), and more clearly depicting the intrahepatic, subcapsular nature of the biloma.

mies performed in patients with cholelythiasis in the last decades, such a complication is becoming even rarer, and recent series have reported indices around $0.8 \%{ }^{(3)}$. The mechanism of development of such complication would be a cascade of events terial colonization and infection, necrosis and perforation ${ }^{(\mathbf{4 , 5})}$. Concomitant development of abscesses or intrahepatic bilomas in such cases has been rarely described ${ }^{(\mathbf{3 , 4})}$. Some authors call such condition "cholecystohepatic communication"(3) rather than "cholecystohepatic fistula"(2), since the latter is considered incorrect for not characterizing a communication between two hollow viscus or between a hollow viscera and an external structure (the skin, for example) $)^{(2)}$; even so, one should consider that such type of "communication" is nothing more than the perforation of a partially or completely intrahepatic GB, with the rupture occurring on the hepatic aspect of the GB rather than intraperitoneally ${ }^{(2)}$.

As the clinical findings of GB perforation are nonspecific, overlapping those observed in cases of non-complicated acute cholecystitis $^{(3,5)}$, imaging methods can be useful tools in the early diagnosis, directly contributing to an immediate management and reduction of morbimortality ${ }^{(2,5)}$. Also, in many cases, the sonographic findings of GB perforation do not differ from those observed in acute cholecystitis (wall thickening and GB distension, pericholecystic fluid, sonographic Murphy sign ${ }^{(3,6)}$, considering that, typically, areas of wall defects and irregularity are small-sized and focal ${ }^{(\mathbf{6})}$; in fact, the earliest signs of imminent perforation may include only GB distension and wall edema ${ }^{(3)}$. In some cases, however, the wall defects may be sufficiently extensive to allow the sonographic identification, characterizing the hole sign ${ }^{(6)}$ demonstrated in the present case, that is considered the sole reliable sonographic sign for the diagnosis of GB perforation ${ }^{(6)}$. 
Although ultrasonography is recommended as a primary imaging method in patients with suspected GB perforation ${ }^{(\mathbf{6})}$, limitations determined by meteorism, for example, may impair the identification of the perforation ${ }^{(3)}$. CT is highly sensitive for detecting the wall defects (tomographic hole sign), reaching $88 \%$ sensitivity in a study ${ }^{(5)}$, which is superior to ultrasonography ${ }^{(\mathbf{1})}$. CT can detect primary alterations of the GB (perforation, wall thickening and contrast enhancement, presence of gas and intramural abscesses, besides radiodense calculi), pericholecystic alterations (fat obliteration, intramural abscesses, bilomas) and extracholecystic alterations (portal vein thrombosis, ascites, pneumoperitoneum) ${ }^{(\mathbf{1 , 5})}$, being also recommended by some authors in all suspicious cases ${ }^{(5)}$. Considering pericholecystic alterations, a study has demonstrated that only the development of abscesses or bilomas is significantly associated with GB perforation ${ }^{(\mathbf{1})}$, caused by the passage of bacteria or infected bile through the site of perforation, leading to pericholecystic inflammatory reaction and, finally, to the development of bilomas or abscesses $^{(\mathbf{1})}$. Although the percutaneous drainage with antibiotic therapy and later elective cholecystectomy might represent an alternative option ${ }^{(2,3)}$, in the present case, the patient had surgical conditions and the option was open cholecystectomy ${ }^{(\mathbf{2 , 4})}$ and biloma drainage.

Finally, the present report highlights a rare and severe complication from acute cholecystitis whose diagnosis must be rapid and accurate to allow the adoption of an appropriate treatment. Considering the relevance of the preoperative imaging diagnosis, it is necessary that the radiologist is able to recognize and distinguish the sono- graphic and tomographic findings which suggest such diagnosis.

\section{REFERENCES}

1. Tsai MJ, Chen JD, Tiu CM, et al. Can acute cholecystitis with gallbladder perforation be detected preoperatively by computed tomography in ED? Correlation with clinical data and computed tomography features. Am J Emerg Med. 2009;27: 574-81.

2. Date RS, Thrumurthy SG, Whiteside S, et al. Gallbladder perforation: case series and systematic review. Int J Surg. 2012;10:63-8.

3. Kochar K, Vallance K, Mathew G, et al. Intrahepatic perforation of the gall bladder presenting as liver abscess: case report, review of literature and Niemeier's classification. Eur J Gastroenterol Hepatol. 2008;20:240-4.

4. Taneja S, Sharma A, Duseja AK, et al. Spontaneous perforation of gallbladder with intrahepatic bilioma. JCEH. 2011;1:210-1.

5. Morris BS, Balpande PR, Morani AC, et al. The CT appearances of gallbladder perforation. Br J Radiol. 2007;80:898-901.

6. Sood BP, Kalra N, Gupta S, et al. Role of sonography in the diagnosis of gallbladder perforation J Clin Ultrasound. 2002;30:270-4. 